\title{
O CINEMA NEGRO ENCONTRA A FORMAÇÃO DE PROFESSORAS: SENSIBILIDADES INTERCULTURAIS, IMPRESSÕES PÓS-COLONIAIS E RECONSTRUÇÕES DECOLONIAIS ${ }^{1}$
}

\author{
THE BLACK CINEMA FINDS THE FORMATION OF TEACHERS: \\ INTERCULTURAL SENSIBILITIES, POSTCOLONIAL IMPRESSIONS \\ AND DECOLONIAL RECONSTRUCTIONS
}

\author{
Fábio José Paz da Rosa \\ Doutor, Universidade Federal do Rio de Janeiro - UFRJ \\ Docente do curso de Pedagogia - UNESA \\ Rio de Janeiro - RJ - Brasil \\ fabiojp83@yahoo.com.br \\ Ana Valéria de Figueiredo da Costa \\ Doutora, Pontifícia Universidade Católica - PUC-RJ \\ Docente do curso de Pedagogia UNESA \\ Docente do curso de Licenciatura em Artes Visuais- UERJ \\ Rio de Janeiro - RJ - Brasil \\ anavaleriadefigueiredo@gmail.com
}

\begin{abstract}
Resumo: Esta pesquisa tem o intuito de compreender de quais modos as licenciandas de um curso de Pedagogia reconstroem conhecimentos diante de filmes com temáticas afro-brasileiras. Para isso, mediante a mostra da obra "A negação do Brasil" (2001), de Joel Zito Araújo, o estudo possibilitou às estudantes-espectadoras potencializar sensibilidades, impressões e reconstruções respectivamente à Interculturalidade, à Pós-Colonialidade e à Pedagogia Decolonial. A metodologia da pesquisa segue as orientações da perspectiva multi/intercultural que possibilita compreender como se constituem as pluralidades e diversidades com o intuito de contribuir para uma formação questionadora da existência das populações negras. As análises demonstraram que as espectadoras relacionaram questões da produção fílmica de acordo com suas condições enquanto mulheres e professoras responsáveis pela formação de seus filhos e alunos em uma perspectiva de questionamento e reelaboração em vista a uma epistemologia pautada em suas trajetórias e existências.
\end{abstract}

Palavras-chave: Cinema negro. Formação de professoras. Pedagogia decolonial.

\begin{abstract}
This research intends to understand how the graduates of a Pedagogy course reconstruct knowledge in front of Afro-Brazilian films. For this, through the exhibition of Joel Zito Araújo's work "The Negation of Brazil" (2001), the study allowed student-spectators to enhance sensibilities, impressions and reconstructions, respectively, to Interculturality, Postcoloniality and Decolonial Pedagogy. The methodology of the research follows the orientations of the multi / intercultural perspective that makes possible to understand how the pluralities and diversities are constituted with the intention of contributing to a questioning formation of the existence of the subjects. The analyzes showed that the spectators related issues of film production according to their conditions as women and teachers responsible for training their children and students in a perspective of questioning and reworking in view of an epistemology based on their trajectories and existences.
\end{abstract}

Keywords: Black cinema. Formation of teachers. Decolonial pedagogy.

Para citar - (ABNT NBR 6023:2018)

ROSA, Fábio José Paz da; COSTA, Ana Valéria de Figueiredo da. O cinema negro encontra a formação de professoras: sensibilidades interculturais, impressões pós-coloniais e reconstruções decoloniais. Eccos - Revista Cientifica, São Paulo, n. 55, p. 1-18, e8360, out./dez. 2020. Disponível em: https://doi.org/10.5585/eccos.n55.8360.

\footnotetext{
${ }^{1}$ Pesquisa produtividade financiada pela Universidade Estácio de Sá.
} 


\section{Introdução}

O cinema, hoje, entendido como arte, está para além do entretenimento. A sétima arte tem nessa lógica a possibilidade de levar os espectadores a se encontrarem consigo mesmos, com suas trajetórias pessoais e com mudança de paradigmas. Uma das principais categorias cinematográficas que trouxe novas perspectivas para as produções imagéticas foi o Cinema Negro.

No contexto do movimento de luta pelos direitos civis dos negros afro-estadunidenses sob a liderança de Martin Luther King Jr. (1929-1968), na década de 1960, e do Movimento Negro Unificado (PRUDENTE, 2011), na década de 1970, no Brasil, é que se iniciam os questionamentos e produções de cineastas negros. Na conjuntura dos diversos movimentos nacionais e internacionais, o Cinema Negro na contemporaneidade é permeado de diferentes ideias e conceitos.

Alguns teóricos concordam que o Cinema Negro tem requisitado cada vez mais artistas afro-brasileiros que elaborem e produzam novas estéticas que garantam o pertencimento étnico, mas que traga implicações em uma perspectiva afirmativa (PRUDENTE, 2011; CARVALHO, 2005, 2012; SANTOS, 2013). Nessa linha de pensamento, a teorização acerca do Cinema Negro é também conceituada em uma perspectiva epistemológica de produção de conhecimentos. Prudente (2011) denomina essa ideia por uma afro-epistemologia que mobiliza o resgate da humanidade africana, muitas vezes desconhecida e omitida.

No caso do Cinema Negro, que nos últimos anos vem sendo ampliado com o intuito de romper com a visão de como a sociedade afro-brasileira foi posicionada, com personagens estereotipados, algumas dessas questões precisam ser especificadas.

A principal especificidade do Cinema Negro brasileiro é a emergência de uma filmografia que necessita se posicionar em uma perspectiva ao mesmo tempo estética e política. Estética no sentido de visibilizar outras possibilidades da presença negra na sociedade e na cultura que possam romper com as imagens até então bastante limitadas: o escravo, o bandido, ou o negro de alma branca ${ }^{2}$. O sentido político volta-se ao reconhecimento de uma população que historicamente perdeu (ou nunca teve) o pertencimento identitário de uma etnia afro e que essa característica implica, mesmo inconscientemente, posicionamentos sociais.

O Cinema Negro, tanto em sentido político quanto estético, vem ganhando novas epistemologias para que os afro-brasileiros construam outros conhecimentos: "Constata-se que o Cinema Negro é uma postura conceitual para expressar o discernimento da nova posição

\footnotetext{
${ }^{2}$ Conferir essas expressões na obra "O negro brasileiro e o cinema” de João Carlos Rodrigues.
} 
sociocultural do afrodescendente, na construção de uma imagem afirmativa do negro e de sua cultura" (PRUDENTE, 2011, p.49). Diante dessa construção sobre o Cinema Negro queremos entender como essa cinematografia pode ser potente para uma formação docente em que novos conhecimentos fundamentem outras perspectivas para um currículo na formação docente em que sujeitos se encontrem com suas trajetórias inseridas na história e na cultura afro-brasileira.

\section{Cinema negro e currículo: possibilidades para uma formação docente intercultural, pós-colonial e decolonial}

A Lei n. $.^{\circ} 10.639 / 2003^{3}$ determinou a implantação das temáticas históricas e culturais das populações afro-brasileiras em todos os níveis de ensino. Nessa perspectiva, Edileuza Penha de Souza (2011) considera que o Cinema Negro nas escolas tem a possibilidade de reafirmar as exigências dessa legislação para "uma educação voltada aos valores do contínuo civilizatório africano" (SOUZA, 2011, p.10).

Além da Lei n. ${ }^{\circ} 10.639 / 2003$, ocorreu a promulgação da Lei n. ${ }^{\circ} 13.006 / 2014$, de autoria do Senador Cristóvão Buarque, que determina a exibição de duas horas mensais de filmes nacionais em escolas públicas. Entendemos que essa legislação pode atentar para que as diversidades étnicas e raciais se façam presentes nas escolhas fílmicas dos docentes. Isto deve ser evidenciado não somente por causa de uma valorização, mas para que estudantes compreendam cada vez mais que os conhecimentos afro-brasileiros são constituintes basilares de nossa cultura.

Apesar das legislações terem diretas implicações nas reformulações curriculares da educação básica, pouco se aborda como tais concepções podem reelaborar a formação docente, mesmo que muitas vezes essa linguagem seja vista apenas como um recurso que visa complementar o conteúdo de uma determinada disciplina. Diferente de outras abordagens artísticas, durante um tempo, os espectadores podem ficar sob a inter-relação entre imagens e sons - motores de novos pensamentos - que permitem questionar e produzir novos conhecimentos. Se esses conhecimentos direcionam para o questionamento e a produção de novos saberes, estamos considerando aqui um diálogo com uma formação de professores fundamentados nas perspectivas da Interculturalidade Crítica, da Pós-colonialidade e da Decolonialidade.

Catherine Walsh (2009) considera que a Interculturalidade Crítica se fundamenta em um questionamento através dos sujeitos que sofreram histórias de submissão. Os antecedentes

\footnotetext{
${ }^{3}$ Altera a Lei n. ${ }^{\circ}$ 9.394, de 20 de dezembro de 1996, que determina as Diretrizes e Bases da Educação Nacional e inclui nos currículos oficiais do ensino fundamental a obrigatoriedade da temática "História e Cultura Afro-Brasileira".
} 
da interculturalidade crítica se evidenciam pelas vozes dos movimentos sociais a partir de problemas estruturais que persistem diante do colonialidade do poder, do saber e do ser. A partir desse reconhecimento, as populações subalternizadas apostariam para uma re-existência de suas vidas que, nas palavras da autora, culminariam em um "imaginário outro" (WALSH, 2009, p.22).

Walter Mignolo afirma que, ao direcionar o olhar para outro locus geo-histórico, "ocorre a produção de conhecimentos" (MIGNOLO, 2003, p.136). Para a produção de novos conhecimentos é preciso analisar e teorizar sobre um determinado saber que se direcione para a autonomia e a libertação em todas as esferas da vida. Dessa forma, a teorização Pós-colonial é construída para transformar o conhecimento - antes visto apenas como representação - para assumir o conhecimento enquanto atuação que visa à transformação epistemológica.

Vera Candau e Luiz Fernandes Oliveira (2010) defendem a formação docente reescrita pela história dos povos afro-brasileiros "possibilitando a mobilização do debate sobre a colonialidade do saber, do poder e do ser, pois a história dos negros no Brasil foi invisibilizada na perspectiva da construção de uma nacionalidade em bases eurocêntricas" (CANDAU e OLIVEIRA, 2010, p.36).

Na perspectiva para se compreender o Cinema Negro como um dos conhecimentos que socialmente tem focado em novas epistemologias estéticas e políticas das populações afrobrasileiras é que esse trabalho se insere. Compreendemos que, ao compormos um currículo de formação de professoras com as temáticas inerentes às questões afro-brasileiras, pretendemos trazer às nossas licenciandas a possibilidade de elas questionarem os processos coloniais e de teorizarem sobre esse reconhecimento, respectivamente um dos principais objetivos da Interculturalidade Crítica e do pensamento Pós-colonial. Assim, podemos também propor superações das realidades que ainda hoje subalternizam populações negras por meio da racialização. É nesse sentido que temos no Cinema Negro a perspectiva de uma formação que proporcione Pedagogias Decoloniais.

Catherine Walsh (2009) considera que uma Interculturalidade crítica se constrói junto à Decolonialidade, pois essa conceituação tem o intuito de tornar visíveis os dispositivos de poder para relacionar o saber, o ser e o poder à própria vida. Ao mesmo tempo, a teórica estadunidense defende a Decolonialidade como uma ferramenta pedagógica capaz de questionar os processos de "racialização, subalternização e inferiorização" (WALSH, 2009, p.25). Por isso, ao se colocar enquanto sendo uma Pedagogia, a Decolonialidade traz as subjetividades para o cerne do debate, não apenas para sua valorização, como também para uma transformação das pessoas como construtoras de conhecimentos forjados em suas histórias e lutas. 
A pesquisa em andamento, desenvolvida em um curso de Pedagogia de uma universidade privada na cidade de Nova Iguaçu localizada na Baixada Fluminense, tem o intuito de repensar a formação docente. Dessa maneira, proporcionamos às licenciandas questionamentos a partir de produções cinematográficas inseridas nas temáticas do Cinema Negro, com vista a desenvolver currículos Interculturais e Decoloniais. Esse posicionamento se tornou evidente quando as licenciandas desenvolveram uma Pedagogia Decolonial a partir do momento em que exercitaram novos pensamentos por meio da exibição fílmica proposta trazendo memórias de suas vivências e ao mesmo tempo elaborando conhecimentos para suas futuras práticas docentes.

A importância dessa pesquisa se efetiva pelo fato de ocorrer em uma instituição de nível superior localizada em uma cidade da Baixada Fluminense, região onde $63 \%$ da população se autodeclarou preta e parda de acordo com dados do Censo 2010 (BRASIL, 2010). Consciente de que a maior parte do público que compõe o curso de Pedagogia da instituição é composta por mulheres negras, essas futuras professoras das séries iniciais do Ensino Fundamental e da Educação Infantil precisam ser formadas para se reconhecerem e se visibilizarem enquanto pertencentes à etnia que se constitui majoritária em contextos históricos e políticos. Acreditamos que o reconhecimento dessa característica é primordial para que essas licenciandas tenham melhores condições para atuarem enquanto docentes desses níveis de ensino.

\section{Trilhando caminhos para uma pesquisa intercultural no processo de formação docente}

A metodologia adotada para o desenvolvimento da pesquisa e da análise das problematizações das alunas-espectadoras em relação ao filme apresentado está pautada pelo Paradigma Multicultural. Encontramos aporte nessa perspectiva, pois a Interculturalidade se constituiu como a forma mais radical do Multiculturalismo. A Interculturalidade é compreendida pela produção mais sensível da diversidade cultural. Vera Candau denomina que o multiculturalismo crítico conceituado por interculturalidade crítica tem por objetivos:

[...] questionar as diferenças e desigualdades construídas ao longo da História entre diferentes grupos socioculturais, étnicos, raciais, de gênero, orientação sexual, entre outros. [...] que a interculturalidade aponta a construção de sociedades que assumam as diferenças como constitutivas da democracia e sejam capazes de construir relações novas, verdadeiramente igualitárias entre os diferentes grupos socioculturais, o que supõe empoderar aqueles que foram historicamente inferiorizados (CANDAU, 2012, p. 244).

Alberto Canen e Ana Ivenicki (2016) apresentam quatro dimensões para uma pesquisa multicultural. A partir delas trilhamos algumas proposições de como poderíamos analisar as 
relações entre o filme sugerido na pesquisa e as sensibilidades e impressões das alunasespectadoras.

Canen e Ivenicki (2016, p. 39), primeiramente, direcionam para um olhar multicultural que é permeado pela "sensibilização" à diversidade cultural dos "próprios professoresformadores-pesquisadores. São esses que constroem/transmitem o conhecimento nas diversas áreas curriculares, assim como dos estudantes com quem vão interagir”. Nesse sentido, os autores propõem mobilizar o pesquisador a se fundamentar em diferentes paradigmas para que sejam capazes de analisar e proporcionar reflexões dos sujeitos que são inerentes a uma determinada cultura.

A segunda dimensão em uma pesquisa multiculturalmente orientada, de acordo com Canen e Ivenicki (2016, p.41), é a pluralidade de paradigmas que "matizam, mesclam e sintetizam contribuições de áreas diversas em perspectivas trans e interdisciplinares”. No caso de nossa investigação, as teorizações sobre Cinema Negro (SOUZA, 2011; RODRIGUES, 2011), produções curriculares multi/interculturais (CANDAU e OLIVEIRA, 2010; GOMES, 2012; CANEN, 2008) e formação docente, pautadas em perspectivas étnicas e raciais (OLIVEIRA, 2014; GOMES, 2008), se inter-relacionam para que possamos pensar e construir epistemologias com e pelas vozes das licenciandas participantes da pesquisa.

A terceira dimensão apresentada por Canen e Ivenicki (2016) é importância da valorização da diversidade cultural e dos embates entre diferentes paradigmas. Em nossa pesquisa, entendemos que esse embate é reflexo dos conflitos, contradições e estranhamentos que são produzidos durante e após as exibições fílmicas, que vão de encontro às imposições históricas e culturais do eurocentrismo e às perspectivas étnicas e raciais que se evidenciam na existência das licenciandas.

Por último, Canen e Ivenicki (2016) defendem que o Paradigma Multicultural de pesquisa deve promover o debate e a compreensão de múltiplas identidades institucionais. A principal ideia é a de [re]construir novas realidades que rompam com os "discursos homogeneizadores" (CANEN; IVENICKI, 2016, p.46). Nessa perspectiva, os autores também orientam para pesquisas em que os participantes são também pesquisadores, "de modo a articular a visão multicultural com o entorno específico em que circula o professor-pesquisador" (CANEN; IVENICKI, 2016, p.48).

As teorizações que aqui nos ajudam a pensar o Cinema Negro na produção curricular da formação docente em uma perspectiva multi/intercultural são chaves conceituais que não deverão conter análises julgadoras do campo de pesquisa. Nessa ótica, as teorias devem tecer o diálogo para compreender "como" e "de que modo" as licenciandas participantes da pesquisa 
reelaboram seus reconhecimentos étnicos e raciais através da potencialidade do Cinema Negro em seus processos de formação docente.

\section{A experiência da exibição do filme: sensibilidades, impressões e reconstruções}

Dos quatro filmes ${ }^{4}$ propostos em nossa pesquisa sobre o Cinema Negro, na perspectiva de uma formação intercultural e decolonial, analisamos A negação do Brasil de Joel Zito Araújo (2001). A escolha desse filme se deu pelo fato de ser uma das exibições em que as estudantes mais demonstraram suas sensibilidades e posicionamentos críticos. $\mathrm{O}$ filme foi exibido no mês de março de 2017, em uma sala de aula da instituição de ensino superior privada, localizada no Município de Nova Iguaçu, RJ. A atividade faz parte de um projeto de pesquisa produtividade sobre Cinema negro e formação docente. A exibição contou com a presença de 43 licenciandas. Após a projeção do filme, com um celular Android, fizemos a gravação em áudio das falas das participantes que quiseram contribuir com suas análises, com duração de quarenta e quatro minutos e oito segundos. Todas as participantes ${ }^{5}$ assinaram o Termo de Consentimento Livre e Esclarecido (TCLE) autorizando a análise de suas falas para fins acadêmicos.

\subsection{Uma formação intercultural pelas sensibilidades}

O filme A negação do Brasil foi assistido com muita atenção pelas licenciandas. A temática proposta pelo diretor Joel Zito Araújo visa problematizar outra linguagem midiática bem presente na vida dos espectadores brasileiros: as telenovelas. Nessa obra fílmica, Araújo questiona os estereótipos e apagamentos dos negros no imaginário das novelas brasileiras. Emergindo as memórias de narrativas televisivas que se utilizavam do Black face até aquelas que restringiam atores e atrizes afro-brasileiros apenas à interpretação de personagens de escravos e ao mesmo tempo recorrendo às falas das atrizes consagradas como Ruth de Souza e Zezé Mota, o cineasta propõe aos espectadores pensar sobre as dificuldades e resistências desses profissionais.

O filme alcança um dos objetivos primordiais quando nos propusemos a debater e problematizar as questões relativas à situação afro-brasileira no campo das artes: o lugar daqueles que têm a voz e se posicionam para serem ouvidos. Constatamos essa intencionalidade

\footnotetext{
${ }^{4}$ Os quatro filmes exibidos no primeiro semestre de 2017 foram "A negação do Brasil” (2001), de Joel Zito Araújo; "Quase dois irmãos" (2005), de Lucia Murat; “Quanto vale ou é por quilo?” (2005), Sérgio Bianchi e "Encontro com Milton Santos ou O Mundo Global visto do lado de cá” (2006) de Sílvio Tendler.

${ }^{5}$ Essa referência às participantes, de presença majoritariamente feminina, é uma forma de posicionamento político que coloca o corpo docente em evidência nas séries iniciais e na educação infantil.
} 
na atenção e no silêncio das espectadoras. O silêncio para ouvir e se ouvir. Para pensar e pensar sobre si. Dessa forma, percebemos que as espectadoras foram aos poucos construindo uma série de inquietações que emergiram em suas falas após a exibição. Assim, as “[...] sensibilidades não são essenciais e não estão inscritas no nascimento dos indivíduos, mas formam-se e transformam-se, criam-se e perdem-se na família e na escola (para os que têm acesso a ela) no decorrer da vida" (MIGNOLO, 2003, p.264).

Se, em grande parte, essas licenciandas tiveram trajetórias de vida que também se construíram sob a ótica racista, ao mesmo tempo elas também foram reconstruindo seus saberes como futuras professoras. Nesse sentido, a exibição de A negação do Brasil, por seus questionamentos, remete reflexões às práticas interculturais e antirracistas para que se tornem integradas aos currículos das séries iniciais do Ensino Fundamental e da Educação Infantil:

\footnotetext{
Aluna 1: Eu gostei [do filme] porque é um bom sinal que nós estamos evoluindo. Apesar de grande massa não se dar conta disso. Dessa discriminação disfarçada. Também foi abordada a questão de pouca oportunidade que os negros têm de emprego na televisão em outros setores. Acho muito bom que é um começo. Muito bom... Precisamos continuar lutando nas escolas [...]
}

Aluna 2: Eu acho que é uma questão que nós como educadores devemos abordar desde os pequenininhos.

A negação do Brasil mostra e discute os reconhecimentos da invisibilidade negra nas telenovelas brasileiras, pautada aqui com as análises das licenciandas. Ao mesmo tempo em que os atores/atrizes negros/negras encontram dificuldades em suas trajetórias, na percepção das espectadoras enunciam-se novas maneiras de ser e estar presente na constituição da cultura afro-brasileira:

\begin{abstract}
Aluna 2: O que me chamou atenção nesse filme... é aquela atriz recém-formada [Maria Ceiça], não tinha uma referência negra para poder atuar, só depois de ela ter ido à Bahia é que se identificou. E também tem aquela outra parte, aquele ator Milton Gonçalves, ele luta... se posiciona, luta pelo espaço dele. Um ato corajoso. Ele poderia ter perdido o emprego, recém-casado, com filhos pequenos. Por causa deles foram abertas portas e muitos negros começaram a fazer pontas.
\end{abstract}

O depoimento da atriz Maria Ceiça no filme permite às alunas-espectadoras compreenderem que nas referências às ancestralidades fundamentadas em seus corpos, na sua cor, é que se inicia a capacidade para reconhecer epistemologias omitidas pelo eurocentrismo. A aluna 2 compreende que a Bahia, antes constituída por olhares, vozes e visibilidades da cultura etnocêntrica, ganhou outros significados no momento em que Ceiça apropria-se de sua ancestralidade e compreende que teria plenas condições de interpretar a personagem Gabriela da célebre obra de "Gabriela, cravo e canela" de Jorge Amado, que posteriormente foi produzido na televisão e o no cinema na interpretação consagrada pela atriz Sônia Braga. 
Essa análise já evidencia construções interculturais na medida em que as espectadoras compreendem que as dificuldades problematizadas no filme também se fazem presentes no contexto escolar, já que as alunas consideram que é nesse espaço que se deve ampliar as possibilidades de o racismo ser superado em alguma medida.

\title{
3.2 Impressões em meio a pós-colonialidade
}

Em uma cultura saturada por construções imagéticas eurocêntricas, a sociedade também se constitui por tais atribuições. No caso das impressões mais enunciadas pelas espectadoras de A negação do Brasil, a categoria "cor da pele" foi a mais utilizada para se reconhecerem as práticas racistas:

\begin{abstract}
Aluna 1: Já tive aluno com problema de chamar o outro de "chocolate", por ele ser escurinho. Deu problema na sala. Ele não gosta, mas porque na família ele aprendeu assim. Então, nós educadores temos que ir trabalhando a mente da criança, ensinando que não é a cor. A cor não tem importância. $O$ que tem importância é o caráter, o ser humano. Não é a cor. Ele tem melhorado, falando com ele que tem leis que punem. Mas mesmo assim... Mas tem um que não gosta, "ih, ele vai sentar na minha frente”, engraçado que ele é moreninho, só porque o outro é mais “queimadinho”, não suporta o menino, mas isso é questão familiar. É duro...
\end{abstract}

Aluna 2: Mas também parei para analisar aquele ator que fez o papel do Xavier [Nelson Xavier], que é mulato, as pessoas não sabem porque tem preconceito, café com leite eles acham que é branco. Mas se você tem avô, passou de branco, preto você é! Somos seres humanos, não cor. Ele só não encontrou tanto preconceito de ter entrado pela porta dos fundos, por ter ficado famoso.

As estudantes apresentam ambiguidades em relação à categoria "cor da pele". Ao mesmo tempo que desconsideram essa característica, elas a enfatizam. A aluna 1 lembra que, em sua prática docente, um aluno que é negro com uma tonalidade de pele menos escura não gosta do outro colega com pele mais escura. Ao utilizar a expressão "mais queimadinho", a licencianda reitera que existe uma importância que é dada pelos discentes nas diferenciações entre tonalidades de pele.

A aluna 2 traz uma análise interessante para se pensar como os diferentes tons da pele negra podem construir desigualdades. A espectadora cita o depoimento dado pelo ator Nelson Xavier que no filme fala sobre as dificuldades daqueles que são pardos se inserirem em uma identidade racial e logo de serem reconhecidos ou não como negros. Ao afirmar "Passou de branco, preto você é", a aluna traz para a construção das ideias a dificuldade de reconhecer as diferentes negritudes. Do mesmo modo, o não reconhecimento reforça as desigualdades, já que há uma tendência de aproximar o pardo à etnia branca.

A cor da pele negra problematizada em suas ambiguidades se insere no que Mignolo (2003), por meio da teorização Pós-colonial, problematiza sobre o colonialismo se enunciar em 
constantes interrupções com a modernidade. Em nossa pesquisa, percebemos como essa relação entre liberdade/opressão se constitui minuciosamente nas análises das licenciandas ao compreenderem que é na estética corporal que se manifesta efetivamente estereotipias, mas também reflexões e estranhamentos diante de determinadas generalizações das populações negras.

As evidências do racismo no campo televisivo, propostas em A negação do Brasil, trouxeram a problematização de a escola ser o território propício para fomentar maneiras eficazes de rompimento com o preconceito racial:

\begin{abstract}
Aluna 3: [...]. Você pode ensinar a teu filho que o preconceito é uma coisa ruim, dentro da tua casa, só que quando seu filho liga uma televisão, quando seu filho assiste uma série, quando seu filho vai na rua, quando seu filho vê inúmeras coisas, com outras pessoas, ele vai ver que tudo é mentira porque o pai dele vai dizer, você é igual a outra pessoa, só que quando ele liga uma televisão, ele não vê um negro raiz. digamos assim protagonista. [...]. Você tem que fazer com que escolas, com que mídias mudem também.
\end{abstract}

Para a aluna 3, a escola, sendo foco de educação diferenciada, contribui para o rompimento de preconceitos, mas também de paradigmas, ou seja, de elaborações de ideias e conceitos que estão para além do ensinar moralmente os filhos a não serem racistas. A discente traz para o debate a função social da escola que, através de suas proposições curriculares, tem capacidade de produzir conhecimentos significativos, principalmente aqueles atravessados pelo histórico da escravidão. O uso do termo "negro raiz" remete a uma construção de visibilidades que podem ser reconhecidas em uma relação com os conhecimentos que foram produzidos especificamente pelas culturas afro-brasileiras.

E como produzir conhecimentos capazes de formar crianças negras orgulhosas de sua diversidade racial, da cor de sua pele, se não elas têm o sustento das raízes que as vinculam às suas origens e às suas existências históricas? Uma das possíveis formas como nos orienta Nilma Lino Gomes (2012) é descolonizar os currículos para que novos paradigmas possam constituir novos processos de educabilidade tanto para a população negra quanto para os não-negros.

\title{
3.3 Reconstruções para uma pedagogia decolonial
}

Uma das potências do documentário A negação do Brasil foi a possibilidade de colocar atores e atrizes afro-brasileiras no local de fala e da produção de conhecimentos. No caso da fala, os artistas se posicionam em um contexto no qual suas trajetórias profissionais são permeadas pelas imposições e apagamentos das suas ancestralidades que, ao mesmo tempo, refletem o modo como as populações afro-brasileiras devem ser invisibilizadas. 
Para além desse cenário, os próprios artistas produzem conhecimentos nos quais conseguem vislumbrar suas potencialidades. Dessa forma, Joel Zito lembra que Ruth de Souza atuou no Teatro Experimental do Negro (TEN) na década de 1940 e na Companhia Cinematográfica Vera Cruz e foi indicada ao prêmio de melhor atriz no Festival de Cinema de Veneza. O cantor e ator Tony Tornado afirma no documentário que, independentemente do papel representado, ele sempre procurou dar o melhor de si.

Apesar da resistência de atores e atrizes afro-brasileiros, ao final do filme, Joel Zito Araújo, após examinar cerca de 400 novelas, chegou à seguinte conclusão: "sendo metade da população do país, ainda não conseguimos ver nossas experiências de vidas e nossos sonhos representados de forma satisfatória no horário nobre das telenovelas brasileiras".

Joel Zito, em sua fala final, expressa a necessidade de produções realizadas com e por negros brasileiros. Ao reivindicar a visibilidade das experiências, o cineasta nos direciona que há saberes e conhecimentos relacionados a essa população que muitas vezes não são considerados. Um deles é a escuta acerca daqueles que estão em culturas de subalternização. Como se colocar atento junto ao outro, de modo que se possa influir em outras maneiras de visibilizar e produzir novos conhecimentos? A aluna 4 apresenta uma dessas possibilidades a partir de sua experiência profissionais com jovens negros e em situação de risco social:

Aluna 4: É o que eu falo para os meus meninos: é muito o lugar da fala. É muito fácil a gente falar de preconceito, eu não sofro preconceito, então, é muito você dar o lugar para o outro falar.

Assim como no documentário A negação do Brasil, essa aluna-espectadora entende que só é possível compreender o preconceito quando se ouve o outro. O lugar para o outro falar é exatamente o espaço de produção de ser e do saber. Para além da importância dos negros nos mais variados grupamentos sociais é importante compreender quais os saberes que essas populações agregam aos diferentes espaços em que se inserem.

O documentário A negação do Brasil também suscitou questionamentos sobre como se ensina a ser negro. Essa questão vem ao encontro do depoimento do ator Maurício Gonçalves ao reiterar a falta de visibilidade dos afro-brasileiros e as estratégias para modificar essa situação: 
Eu acho que a nossa novela, no final do século XX, não consegue atender à diversidade racial em nosso país e acho mais ainda, não sei, é uma intuição... se ela abriu nesse final de 90, no finalzinho ela se torna muito estereotipada: a negona boazuda, o negão jogador de futebol, o negão ladrão, e cada vez menos os atores negros estão atuando, eles estão todos contratados pela Globo, mas eles não estão atuando. Se nós somos $47 \%$, é preciso que tenhamos pelo menos $30 \%$ atuando em cada novela, afinal de contas a televisão é regida pelo governo. É preciso que exista essa questão também didática, para que nós melhoremos essa relação da pirâmide social. É preciso que os negros pobres tenham exemplos, já que a televisão é um grande veículo que atinge a todos nesse país, precisamos ter os nossos médicos, os nossos advogados dentro da trama e não fora.

A visibilidade dos exemplos em novos posicionamentos sociais, segundo Maurício Gonçalves, é essencial para que, de forma didática, as populações afro-brasileiras construam aprendizagens que sejam capazes de romper com o modus operandi que as constituíram. Para isso, é preciso que as negritudes possam não apenas reconstruir os conhecimentos com suas vozes, olhares e posicionamentos, mas também pensar em novas formas de como ensinar e aprender por meio das epistemologias produzidas pelas negritudes. As alunas-espectadoras comentaram sobre algumas das formas em como devem ensinar seus filhos e filhas a serem negros e negras. A aluna 5 falou da experiência de ser uma mãe de um filho negro:

\begin{abstract}
Aluna 5: [...] eи percebi, que eu preciso prepará-lo para isso. Eu tive que dizer pra ele: você precisa andar com documentos, podem te julgar um menino sem família, como um menino marginal. E aí eu tive que conversar com ele: você precisa andar com documento, você precisa saber se expressar. Você não precisa ter medo de polícia. Mas você também não pode correr de polícia.
\end{abstract}

No caso da aluna citada acima, ensinar como ser um menino negro requer uma vigilância para que o filho não seja confundido com uma criança que comete delitos. A aluna espectadora relata sua forma de ensinar ao filho consciente das idealizações que a sociedade constrói, nas quais os menores que cometem crimes seriam meninos negros. Ainda há uma dificuldade das culturas subalternizadas, por uma questão de sobrevivência histórico-social, de serem visibilizados de forma diferente das colonialidades já que essa visão as mantém sob formas de controle.

No caso dos negros, essa aprendizagem e esse controle se efetivam primeiramente pelos corpos, já que só o fato de serem negros já os coloca em condição de permanente suspeita. Por isso, a questão de muitas mães considerarem que seus filhos devam sempre portar sua documentação, e que saibam se expressar corretamente para que diminuam as possibilidades das referências à criminalidade.

O controle dos corpos negros é uma das primeiras aprendizagens com as quais as crianças e jovens negros precisam saber lidar para terem a possibilidade de usufruir o direito à sobrevivência, de acordo com os códigos impostos pela colonialidade. A didática é desenvolvida de forma a não demonstrar incoerências determinadas por perspectivas 
eurocêntricas, tanto para os opressores quanto para os oprimidos. Como menciona a aluna 5, o filho não precisa expressar medo, mas ao mesmo tempo não pode correr. Esse corpo sob eterna suspeita precisa minuciosamente aprender a ser negro, adentrando aos jogos do poder:

\begin{abstract}
Aluna 6: Quando eu comecei a trabalhar com jovens e dos meus jovens a maioria é negra. E a gente trabalha para área voltada ao mercado de trabalho. E eu recebo muito não. E por que que eu recebo muito não? Porque as pessoas brancas que são mais contratadas. Quando eu recebo vagas assim, pra recepcionista ou para outras áreas afins, eles mandam o perfil: pessoas de cabelo liso, sabe todo um perfil, que tu olha... os meus jovens não são assim. Eles têm um outro perfil. E a maioria pede: manda foto. Porque se não tiver dentro daquele perfil, eles não contratam.
\end{abstract}

A análise da licencianda nos fala dos jovens que ela forma para ingressar no mercado de trabalho, bem como das suas dificuldades, já que, ao que parece, o perfil dos jovens negros não é analisado pelas habilidades técnicas e sim pelo fenótipo. Tais considerações revelam que as imagens pensadas e produzidas pelas e para as populações negras precisam de ressignificações com e pelos corpos. Reconhecer e olhar para além dos estereótipos significa produzir outros olhares nos quais se descubram a infinita potencialidade de conhecimento das experiências culturais negras, os quais necessitam ser aprendidos tanto por negros quanto por não negros.

Stuart Hall (2003) lembra que as formas de produção corpóreas que se desenvolveram em meio aos processos opressivos também permitiram que ancestralidades, estéticas e oralidades fossem desenvolvidas com o intuito de elaborar conhecimentos interculturais capazes de constituir povos que não eram somente africanos, mas que tampouco eram europeus. Então, temos outra possibilidade didática e curricular na perspectiva decolonial ao conceber as populações afro-brasileiras a partir do momento em que concebemos as identidades específicas enquanto produtoras de novas práticas, fundamentadas em epistemologias de culturas até então posicionadas em subalternidades. Podemos visibilizar essa potencialidade na fala da aluna 2:

\footnotetext{
Aluna 2: A gente precisa formar crianças fortes: [afirmar] que ele é bonito sim, que ele é especial, que ele é importante, pra quando acontecer essas coisas, de ele não se identificar, a princesa negra, não ficar triste, é lutar pelo espaço, correr atrás, entendeu? Estudar, correr atrás.
}

Se historicamente as colonialidades produziram imagens que remetem as culturas negras às suas próprias impossibilidades de desenvolverem conhecimentos relacionando suas ancestralidades, hoje temos a urgência de reconstruir outras visibilidades nas quais as diferenças e diversidades se posicionem como as primeiras maneiras de constituição e reconhecimento dos sujeitos. A aluna 2 direciona seu pensamento para essa perspectiva. Ensinar às crianças negras a visibilizarem e a reconhecerem sua beleza é uma aprendizagem essencial para emergir as identidades étnico-raciais. Afinal, como elas poderão compreender que têm plenas condições 
de estudar e ingressar no mercado de trabalho se elas não se veem referenciadas? Assim como A negação do Brasil mostrou para as alunas-espectadoras que as colonialidades se repetem constantemente, numa tentativa de mostrar aspectos acerca das negritudes, sobre o que ainda é de interesse do eurocentrismo, percebemos que há uma busca por repensar as negritudes por meio dos processos educacionais de forma propositiva.

Por isso, Miranda (2013) considera que é preciso ampliar as fronteiras epistêmicas do educar no contexto escolar, já que existe uma constante pedagogia que se produz no meio midiático. Segundo a teórica, essas pedagogias apresentam "recomposições epistêmicas" (MIRANDA, 2013, p. 102). Apesar das relações de poder presentes na elaboração do currículo escolar estarem em constantes negociações entre políticas educacionais e concepções curriculares e didática, Miranda (2013) afirma que a formação de professores/as nos coloca próximos de realidades dissonantes que muitas vezes dificulta a produção de dialogias interculturais. Essa constatação se deve principalmente ao fato de a escola ser um espaço frágil em que as diversas disputas de poder concorrem para estabelecer questões de caráter mais administrativo do que linguístico. (MIRANDA, 2013).

Desse modo, as análises das espectadoras fomentaram novos olhares de uma Pedagogia decolonial por meio do Cinema negro ao demonstrarem outras possíveis estéticas por meio de suas reflexões e oralidades em que os corpos negros devem romper com os estereótipos para produzirem sentido e presença no mundo. Tanto o sentido quanto a presença se fazem pelas experiências vividas e por aquelas que estão para serem elaboradas como as mencionadas por nossas estudantes, através suas peles e de seus corpos para, assim, potencializarem outros conhecimentos em que essas futuras professoras tragam suas maneiras de ensinar e aprender.

\section{Por novas epistemologias}

Na perspectiva de uma formação docente intercultural, o cinema pode evidenciar muitas questões que transitam entre o reconhecimento dos limites impostos pelas colonialidades e os respectivos rompimentos com tais estereótipos como a vista na construção de uma Pedagogia Decolonial.

As licenciandas-espectadoras, ao entrarem em contato com a cinematografia de Joel Zito Araújo, em A negação do Brasil, conseguiram expor suas sensibilidades, impressões e também possivelmente reconstruíram seus pensamentos ao contrapor ideias sobre sua negritude, a de seus filhos, parentes e alunos. Como salientam Canen e Ivenicki (2016, p.48), 
as metodologias fundamentadas nas perspectivas multiculturais "buscam contribuir de forma ativa e participativa no desafio" de despertar as identidades historicamente silenciadas.

Se o filme A negação do Brasil questiona estereótipos e ausências dos afro-brasileiros na teledramaturgia nacional, as licenciandas também relacionam a proposta do filme aos espaços de suas futuras atuações profissionais. Logo, se as produções cinematográficas denunciam o projeto colonial de produzir invisibilidades e estereotipias das negritudes, as licenciandas-espectadoras compreendem que, junto aos currículos escolares, tal problemática é também pertinente.

Ao analisarem a escola como o outro espaço de formação, as licenciandas reconhecem que essa instituição tem uma importância para a busca de novas concepções, já que deverá desenvolver conhecimentos voltados às epistemologias que traduzam suas identidades entre as opressões e a pujança da cultura afro-brasileira. Essa constatação, surgida da análise fílmica, dialoga com a intencionalidade do cineasta Joel Zito Araújo que, apesar das estruturas eurocêntricas ainda serem determinantes para a formação de pensamentos e práticas, essas são constantemente questionadas e desafiadas. Nesse sentido, há nessa relação entre colonialidade e outra realidade capaz de evidenciar novas estéticas das populações negras, como problematizado na perspectiva Pós-colonial, um gesto de resistência para exprimir ideias ou sentimentos.

Da mesma forma que a teledramaturgia exige um maior quantitativo de negros para abordar os conhecimentos pertinentes às culturas afro-brasileiras como demonstrado em $A$ negação do Brasil, as escolas precisam produzir um currículo em que essa realidade se faça constante para a denúncia das opressões, mas principalmente para compreender como essa parcela significativa da sociedade concebeu resistências, e vem historicamente reexistindo.

As licenciandas-espectadoras chegaram à conclusão de que, mesmo ao negarem a cor como um elemento importante para diferenciar os sujeitos, elas reiteram como seus alunos [des]aprendem práticas racistas, isto é, que negros com tons mais claros de pele podem exercitar o racismo contra aqueles de pele mais escura; que jovens negros não conseguem uma posição no mercado de trabalho pela questão dos seus fenótipos.

Assim, as licenciandas tecem conhecimentos em que a existência de crianças e jovens negros são pautadas pelas formas como as colonialidades vão sendo construídas em seus corpos. Entre possibilidades de controle por meio das instituições de constante vigilância e o empoderamento da beleza negra, são nos corpos que os conhecimentos epistemológicos se mostram mais evidentes tanto para negar quanto para potencializá-lo. 
Na elaboração de uma Pedagogia decolonial, acreditamos que a análise do filme $A$ negação do Brasil, por parte das licenciandas, abre reflexões acerca de como constituir currículos em uma formação docente em que se busque tanto fundamentações teóricas quanto metodológicas para que os conhecimentos epistemológicos das culturas afro-brasileiras se efetivem na existência, principalmente, das populações negras.

Acreditamos que o cinema proporciona a capacidade desses sujeitos reelaborarem novos conhecimentos primeiro porque o filme faz as espectadoras se colocarem em um momento de escuta. Um aspecto presente em grande parte das perspectivas africanas, a obra fílmica tornase um meio em que a oralidade se evidencia como prática ancestral. Em seguida, as licenciandas-espectadoras transformam o que até então foi colocado como uma possível verdade, ou seja, reexistir através do reconhecimento da cor da pele de seus corpos.

O que o reconhecimento dessas vozes, cores e corpos negros nos ensinam? Esse questionamento poderá ser respondido na medida em que as populações negras, ao expressarem resistência, forem construindo conhecimentos capazes de tornar suas existências não somente transmissoras, mas, principalmente produtoras dos saberes ancestrais.

\section{Considerações finais}

O encontro com uma cinematografia negra por meio de A negação do Brasil nesse curso de formação de professoras suscitou nas licenciandas o interesse por problematizar questões que são inerentes as suas existências e presenças em uma sociedade marcadamente racista. Essa realidade as despertou para um posicionamento Intercultural que se caracteriza por questionamentos que se iniciaram sobre a cor da pele como um elemento desencadeador de invisibilidades e valorizações e culminou em pensamentos capazes pensar em outras produções curriculares para a formação no magistério voltado às séries iniciais do Ensino Fundamental e à Educação Infantil.

É exatamente no cerne da escola que, para as licenciandas, algumas das problemáticas pós-coloniais parecem se evidenciar. Essa teorização é reconhecida tanto histórica quanto esteticamente, inclusive com maiores possibilidades para outras construções curriculares fundamentadas nos conhecimentos, como conceituou uma das licenciadas, quando citou "negro raiz".

As possíveis propostas para um ensino em que novas epistemologias fundamentem uma formação transformadora das estruturas vigentes nas análises desenvolvidas por nossas licenciandas reconhecem que isso se efetiva primeiro pelo reconhecimento e valorização da 
estética negra de seus alunos. Apesar de não ser o único componente capaz de fundamentar epistemologias, as corporeidades se tornam as primeiras formas de (re)existências propulsoras de outras epistemologias. Esse reconhecimento pode ser capaz de nos fazer, inseridos em objetivos da Pedagogia Decolonial, a [des]aprender com intuito de compreender perspectivas históricas e sociais pautadas primordialmente nas trajetórias das populações afro-brasileiras.

\section{Referências}

A NEGAÇÃO do Brasil. Direção: Joel Zito Araújo. Elenco: Léa Garcia, Maria Ceiça e Milton Gonçalves, Ruth de Souza e mais. 2001. Rio de Janeiro: Estúdio de Mixagem: Equipe Estúdios Mega. 1 filme documentário (1h32min), 35mm, Colorido e P\&B.

BRASIL. IBGE. Instituto Brasileiro de Geografia e Estatística. Censo 2010. Cidades. Nova Iguaçu. Disponível em: http://cidades.ibge.gov.br/xtras/perfil.php? lang=\&codmun=330350\&search=rio-de-janeiro|nova-iguacu. Acesso em: 15 Dez 2017.

BRASIL. Lei n. 10.639, de 09 de janeiro de 2003. Estabelece as diretrizes Curriculares Nacionais para a Educação das Relações Étnico-Raciais e para o Ensino de História e Cultura Afro-Brasileira e Africana. Diário Oficial da União, Brasília, DF: Presidência da República, 09 jan. 2003.

BRASIL. Lei n. 13.006, de 26 de junho de 2014. Estabelece a exibição de filmes de produção nacional que constituirá componente curricular integrada à proposta curricular da escola sendo a sua exibição obrigatória por no mínimo duas horas mensais. Diário Oficial da União, Brasília, DF: Presidência da República, 26 jun. 2014.

BRASIL. MINISTÉRIO DA SAÚDE, CONSELHO NACIONAL DE SAÚDE. Manual operacional para comitês de ética em pesquisa. Brasília (DF): Ministério da Saúde, 2002.

CANDAU, Vera. Diferenças culturais, interculturalidade e educação em Direitos Humanos. In: Educ. Soc., Campinas, v. 33, n. 118, p. 235-250, jan.-mar. 2012.

CANDAU, Vera; OLIVEIRA, Luís Fernandes de. Pedagogia Decolonial e Educação antirracista e intercultural no Brasil. In: Educação em Revista, Belo Horizonte, vol.26, n.01, p.15-40, jan.-abr. 2010. ISSN 0102-4698.

CANEN, Alberto; IVENICKI, Ana. Metodologia da Pesquisa: rompendo fronteiras curriculares. Rio de Janeiro: Moderna, 2016.

CANEN, Ana. A pesquisa multicultural como eixo da formação docente: potenciais para a discussão da diversidade das diferenças. In: Ensaio, v.16, n.59, p. 297-308, abr/jun.2008.

GOMES, Nilma Lino. Relações étnico-raciais, educação e descolonização dos currículos. In: Revista Currículo sem Fronteiras, Belo Horizonte, vol.12, n.1, p.98-109, jan.-abr. 2012. 
GOUVÊA, Fernando César Ferreira; OLIVEIRA, Luiz Fernandes de; SALES, Sandra Regina (Orgs.). Educação e Relações Étnico-Raciais: entre diálogos contemporâneos e políticas públicas. Petrópolis (RJ): De Petrus [et alii]; Brasília (DF): Capes, 2014.

HALL, Stuart. Da diáspora: identidades e mediações culturais. Liv SOVIK (Org.); Tradução de Adelaine La Guardia Resende [et al.]. Belo Horizonte: Editora UFMG, 2003.

MIGNOLO, Walter. Histórias locais/ Projetos globais: colonialidade, saberes subalternos e pensamento liminar. Tradução de Solange Ribeiro de Oliveira. Belo Horizonte: Editora UFMG, 2003.

MIRANDA, Cláudia. Currículos decoloniais e outras cartografias para uma educação das relações étnico-raciais: desafios político-pedagógicos frente à Lei n. 10.639/2003.

PRUDENTE, Celso. Cinema Negro: Pontos reflexivos para a compreensão da importância II Conferência de intelectuais da África e da Diáspora (Ensaios). Brasília, 2011, p. 48- 50. Revista da ABPN , v. 5, n. 11, jul.- out , p. 1.00-118, 2013.

RODRIGUES, João Carlos. O negro brasileiro e o cinema. Rio de Janeiro: Pallas, 2011. SANTOS, Júlio César. A quem interessa um cinema negro? Revista da ABPN, v. 5, n. 9 nov.-fev., p. 98-106, 2013.

SOUZA, Edileuza Penha. Negritude, Cinema e Educação: caminhos para implementação da Lei n.10.639/2003. Belo Horizonte: Mazza, 2011.

WALSH, Catherine. Interculturalidad crítica y educación intercultural. In: VIAÑA, Jorge; WALSH, Catherine; TAPIA, Luis (Orgs.). Construyendo interculturalidad crítica. La Paz: Instituto Internacional de Integración Andrés Bello, 2009, p.75-96. 